\title{
Nonlinear Modeling and Analysis of R.C. Framed Buildings Located in a Near-Fault Area
}

\author{
Fabio Mazza ${ }^{*}$ and Mirko Mazza
}

Dipartimento di Strutture, Università della Calabria, 87036 Rende Cosenza, Italy

\begin{abstract}
Structural damage to r.c. buildings located in a near-fault area has been observed during strong ground motions, with long-duration horizontal pulses and high values of the ratio between the peak value of the vertical acceleration and the analogous value of the horizontal acceleration. The design provisions of current seismic codes are generally not very accurate for assessing the structural effects of near-fault ground motions. In the present work, six- and twelve-storey r.c. spatial frames are designed according to the provisions of the Italian seismic code, considering horizontal and vertical seismic loads in a high-risk seismic region and assuming low and high ductility classes. A lumped plasticity model based on the Haar-Kàrmàn principle is used to describe the inelastic behavior of the r.c. frame members. In particular, the lumped plasticity model for a column includes a piecewise linearization of the bounding surface of the axial load-biaxial bending moment elastic domain, at the end sections where inelastic deformations are expected. Moreover, the lumped plasticity model for a girder takes into account the potential plastic hinges along the span, due to the vertical ground motion, so avoiding the computational effort required by the sub-discretization of the frame member. The nonlinear dynamic response of the test structures is studied with reference to the horizontal and vertical components of near-fault records. The occurrence of a directivity effect at arbitrary orientations is checked rotating the horizontal components of the selected motions, rather than considering only fault-normal and fault-parallel orientations.
\end{abstract}

Keywords: R.c. spatial frames, lumped plasticity model, axial load-biaxial bending, nonlinear dynamic analysis, near-fault ground motions.

\section{INTRODUCTION}

Near-fault ground motions, like those recorded at L'Aquila in 2009, have different characteristics from those of far-fault ground motions and can induce unexpected structural damage in r.c. buildings. More specifically, these motions can exhibit long-duration horizontal pulses generated by a forward-directivity effect [1-4]. Moreover, high values of the ratio $\alpha_{\mathrm{PGA}}$ between the peak value of the vertical acceleration $\left(\mathrm{PGA}_{V}\right)$ and the analogous value of the horizontal acceleration $\left(\mathrm{PGA}_{\mathrm{H}}\right)$ can also occur. In particular, the pulsetype nature of a (horizontal) near-fault ground motion can induce ductility demands at the end sections of both girders and columns, which also depend on the direction and position of the structure with respect to the rupture surface [5-9]. On the other hand, high values of the acceleration ratio can notably modify the axial load in r.c. columns, even producing tension and high compressive forces; moreover, plastic hinges are expected along the span of r.c. girders, especially in the upper storeys [10-12].

The nonlinear dynamic response of medium-to-high rise r.c. framed buildings subjected to horizontal (bidirectional) and vertical components of near-fault ground motions is studied in the present work in order to evaluate the effectiveness of the Italian seismic code NTC08 [13]. To reduce the

*Address correspondence to this author at the Dipartimento di Strutture, Università della Calabria, 87036 Rende (Cosenza), Italy;

Tel: +39 (0)984-496908; Fax: +39 (0)984-494045;

E-mail: fabio.mazza@unical.it computational effort, a lumped plasticity model based on the Haar-Kàrmàn principle is used to model the inelastic behavior of the r.c. frame members [14-16]: for a column, a piecewise linearization of the bounding surface of the axial load-biaxial bending moment elastic domain is used at the end sections, where inelastic deformations are expected; for a girder, the elastic-plastic solution is evaluated only at the end sections but the potential plastic hinges along the span, due to the vertical ground motion, are also checked.

\section{LUMPED PLASTICITY MODELING OF A R.C. COLUMN}

Many nonlinear modeling strategies for a r.c. column subjected to biaxial bending and axial force are available in literature [17]. For this type of element, a good simulation of the response can be obtained by a piecewise linearization of the bounding surface of the axial load-biaxial bending moment elastic domain, at the end sections where inelastic deformations are expected [15]. Each flat surface corresponds to a plastic strain mechanism for the cross-section (Fig. 1), defined by the axial strain $\varepsilon_{P}$, along the longitudinal axis $x$, and by the curvatures $\chi_{P y}$ and $\chi_{P z}$, along the principal axes $y$ and $z$, referring to the (geometric) centroid of the section. These strains and the corresponding generalized stresses are collected in the vectors

$$
\begin{aligned}
& \boldsymbol{\varepsilon}_{P}=\left[\varepsilon_{P}, \chi_{P y}, \chi_{P z}\right]^{T} \\
& \boldsymbol{\sigma}=\left[N, M_{y}, M_{z}\right]^{T}
\end{aligned}
$$




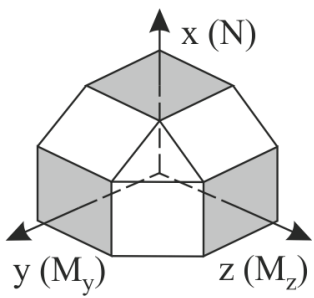

(a)

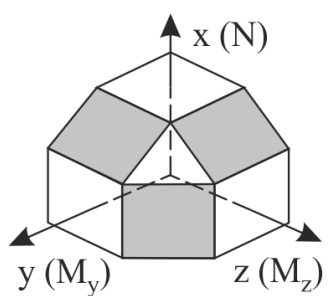

(b)

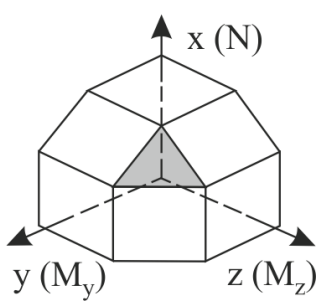

(c)

Fig. (1). Flat surfaces approximating the elastic domain for the end sections of a r.c. column.

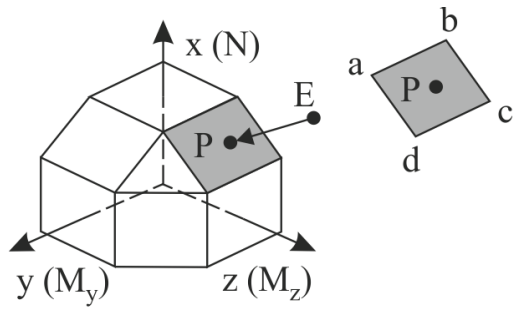

(a)

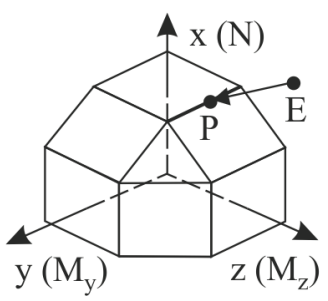

(b)

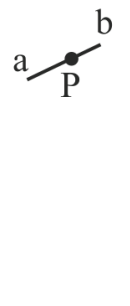

Fig. (2). Return mapping on the flat surfaces approximating the elastic domain of a r.c. column.

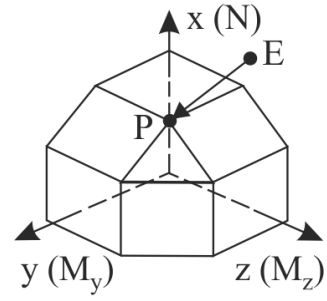

(c)
Denoting with $\boldsymbol{\sigma}_{P k}$ the plastic stresses related to $\boldsymbol{\varepsilon}_{P k}=\boldsymbol{n}_{k}$, the elastic domain $g(\sigma)=0$ can be approximated by $n_{f s}$ flat surfaces $g_{k}(\sigma)$, each defined by a different (normal) direction $\boldsymbol{n}_{k}$. In the proposed model, the axial load-biaxial bending moment bounding surface of the elastic domain is discretized by: 6 surfaces normal to the principal axes $x, y$ and $z$ (e.g. Fig. 1a); 12 surfaces normal to the bisections of the $y-z, x-y$ and $x-z$ principal planes (e.g. Fig. 1b); 8 surfaces normal to the bisections of the octants (e.g. Fig. 1c). The piecewise linearized elastic domain is characterized by the corresponding 26 columns of the matrix

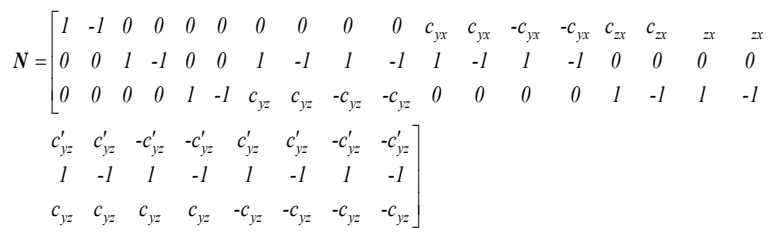

where each column represents a vector $\boldsymbol{n}_{k}$ which is defined starting from

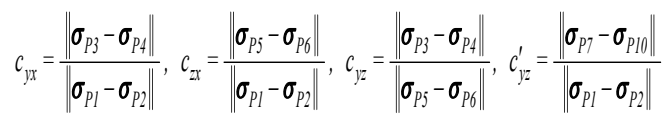

with the plastic generalized stresses defined as

$$
\begin{aligned}
& \boldsymbol{\sigma}_{P 1}=\left[\begin{array}{c}
N_{P 1} \\
0 \\
0
\end{array}\right], \boldsymbol{\sigma}_{P 2}=\left[\begin{array}{c}
N_{P 2} \\
0 \\
0
\end{array}\right], \boldsymbol{\sigma}_{P 3}=\left[\begin{array}{c}
N_{P 3} \\
M_{P, 3} \\
0
\end{array}\right], \boldsymbol{\sigma}_{P 4}=\left[\begin{array}{c}
N_{P 4} \\
M_{P y 4} \\
0
\end{array}\right], \boldsymbol{\sigma}_{P S}=\left[\begin{array}{c}
N_{P S} \\
0 \\
M_{P z 5}
\end{array}\right], \boldsymbol{\sigma}_{P 6}=\left[\begin{array}{c}
N_{P 6} \\
0 \\
M_{P 26}
\end{array}\right]
\end{aligned}
$$

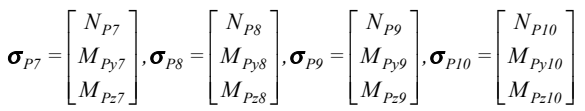

The components of the generalized plastic stress vector $\sigma_{P k}$ can be evaluated by the equilibrium equations:

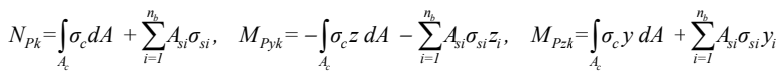

where elastic-perfectly plastic constitutive laws are assumed for both concrete $\left(\sigma_{c}-\mathcal{E}_{c}\right)$ and steel $\left(\sigma_{s}-\mathcal{E}_{s}\right)$, assuming a positive sign for tensile stresses and strains. In eq.(6), $n_{b}$ is the number of longitudinal bars while $\left(y_{i}, z_{i}\right)$ and $A_{s i}$ define, respectively, the position and area of each bar. In particular, once the plastic strain mechanism of the cross-section corresponding to the vector $\boldsymbol{n}_{k}\left(k=1 . . n_{f s}\right)$ is considered, the maximum compressive strain in concrete $\left(\mathcal{E}_{c \text { max }}\right)$ and the maximum tensile strain in longitudinal steel reinforcement $\left(\varepsilon_{\text {smax }}\right)$ are evaluated, avoiding values greater than the corresponding ultimate ones (e.g. $\varepsilon_{c u}=0.35 \%$ and $\varepsilon_{s u}=1 \%$ ), so obtaining the position of the neutral axis and the compressed concrete area $\left(A_{c}\right)$.

At each step of the analysis, the elastic-plastic behavior, once the initial state and the incremental load are known, can be obtained by using the Haar-Kàrmàn principle. It states that, among all the generalized stress fields $\sigma$ satisfying equilibrium, the elastic-plastic solution $\boldsymbol{\sigma}_{E P}$ is that with the minimum distance, in terms of complementary energy $\Pi_{c}$, from the elastic solution $\boldsymbol{\sigma}_{E}[14]$

$$
\Pi_{c}\left(\boldsymbol{\sigma}_{E P}\right)=\frac{L}{2} \int_{0}^{l}\left(\boldsymbol{\sigma}_{E P}-\boldsymbol{\sigma}_{E}\right)^{T} \boldsymbol{D}_{c}^{-1}\left(\boldsymbol{\sigma}_{E P}-\boldsymbol{\sigma}_{E}\right) d \xi=\min .
$$

$\xi(=x / L)$ being a nondimensional abscissa, $L$ the length of the beam element and $\boldsymbol{D}_{c}$ the elastic matrix of a column. The plastic admissibility conditions

$$
g_{k}\left(\sigma_{E P}\right) \leq 0 \text { for } k=1 . . n_{f_{s}}
$$

also have to be satisfied at the end sections of the beam element. More specifically, the first step of the return-mapping algorithm consists of the identification of the octant of the elastic domain $\left(N-M_{y}-M_{z}\right)$ where the elastic solution $\sigma_{E}$, represented by the point E, lies (Fig. 2). Afterwards, the elasticplastic solution $\boldsymbol{\sigma}_{E P}$ represented by the point $\mathrm{P}$ is obtained by the closest-point projection method, referring to the active flat surface of the elastic domain and checking that the point $\mathrm{P}$ lies inside it (Fig. 2a). Otherwise, the point $\mathrm{P}$ can be located along the active line (Fig. 2b) or at the active corner (Fig. 2c) resulting from the intersection of two or more flat surfaces, respectively. 


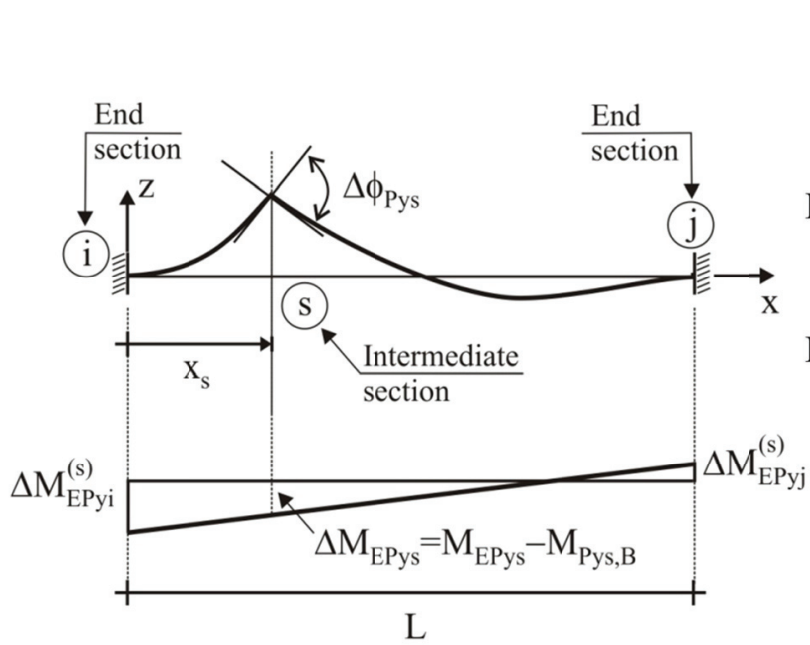

(a)

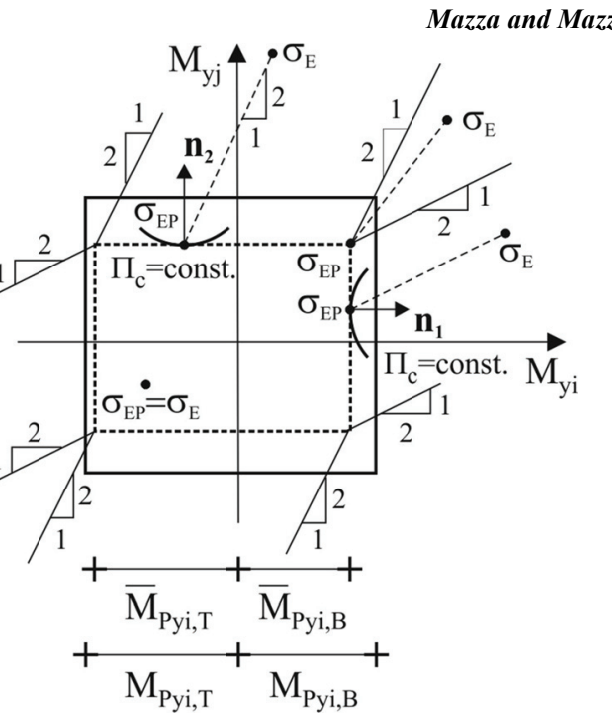

(b)

Fig. (3). Haar-Kàrmàn solution for a r.c. girder.

\section{LUMPED PLASTICITY MODELING OF A R.C. GIRDER}

The lumped plasticity model adopted for r.c. girders [15] evaluates the elastic-plastic solution only at the end sections $(i$ and $j$ ) in the vertical plane of bending (i.e. $x-z$ plane). Potential inelastic deformations lumped at $n_{s}$ intermediate sections along the span, due to the vertical ground motion, are also checked. In order to avoid the computational effort relating to the sub-discretization of the frame member, the elastic solution at the end section $i(j)$ is modified taking into account the possible inelastic effects occurring at an intermediate section $s\left(s=1 . . n_{s}\right)$, besides those at the end section $j$ (i). In particular, when a plastic (flexural) distortion

$$
\Delta \phi_{P y s}=\Delta M_{E P y s}\left(\frac{4 E I_{y}(1-p)}{L}\left(3\left(\frac{x_{s}}{L}\right)^{2}-3\left(\frac{x_{s}}{L}\right)+1\right)\right)^{-1}
$$

resulting from an elastic-plastic moment $M_{E P y s}$ greater than the corresponding plastic moment occurs at an intermediate section of abscissa $x_{s}$ (Fig. 3a), the corresponding moments at the end sections are evaluated as

$$
\begin{aligned}
\Delta M_{E P y i}^{(s)} & =\frac{2 E I_{y}(1-p)}{L}\left(3\left(\frac{x_{s}}{L}\right)-2\right) \Delta \phi_{P y s} \\
\Delta M_{E P y j}^{(s)} & =\frac{2 E I_{y}(1-p)}{L}\left(3\left(\frac{x_{s}}{L}\right)-1\right) \Delta \phi_{P y s}
\end{aligned}
$$

$p$ being the hardening ratio of the $M-\chi$ law. Collecting the generalized stresses in the vector

$$
\boldsymbol{\sigma}=\left[M_{y i}, M_{y j}\right]^{T}
$$

the elastic-plastic solution satisfying equilibrium is obtained, according to the Haar-Kàrmàn principle, minimizing the complementary energy

$$
\Pi_{c}\left(\boldsymbol{\sigma}_{E P}\right)=\frac{L^{2}}{2} \int_{0}^{l}\left(\boldsymbol{\sigma}_{E P}-\boldsymbol{\sigma}_{E}-\Delta \boldsymbol{\sigma}_{E P}^{(s)}\right)^{T} D_{g}^{-l}\left(\boldsymbol{\sigma}_{E P}-\boldsymbol{\sigma}_{E}-\Delta \boldsymbol{\sigma}_{E P}^{(s)}\right) d \xi=\text { min. }
$$

where $\boldsymbol{D}_{g}$ is the elastic matrix of a girder; the plastic admissibility condition

$$
g\left(\sigma_{E P}\right) \leq 0
$$

also has to be satisfied at the end sections of the girder. In particular, the (uniaxial) top (T) and bottom (B) plastic moments at the end sections

$$
\begin{aligned}
& \boldsymbol{\sigma}_{P, T}=\left[M_{P y i, T}, M_{P y j, T}\right]^{T} \\
& \sigma_{P, B}=\left[M_{P y i, B}, M_{P y j, B}\right]^{T}
\end{aligned}
$$

are modified during the nonlinear analysis, assuming the following values when a plastic distortion occurs at an intermediate section (see Fig. 3b)

$$
\begin{aligned}
& \overline{\boldsymbol{\sigma}}_{P, T}=\left[\bar{M}_{P y i, T}, \bar{M}_{P y j, T}\right]^{T} \\
& \overline{\boldsymbol{\sigma}}_{P, B}=\left[\bar{M}_{P y i, B}, \bar{M}_{P y j, B}\right]^{T}
\end{aligned}
$$

The elastic-plastic solution of the problem defined by the eq.(13) and eq.(14) can be obtained by a predictor-corrector procedure. It is triggered evaluating the elastic-plastic solution at an end section (e.g. end section $i$ ) by the formula:

$$
M_{E P y i}^{(0)}=\max \left(-\bar{M}_{P y i, T}, \min \left(\bar{M}_{P y i, B}, M_{E y i}+\sum_{s=1}^{n_{s}} \ddot{A} M_{E P y i}^{(s)}\right)\right)
$$

Afterwards the elastic-plastic solution is alternately evaluated at the end sections $i(j)$ and $j(i)$

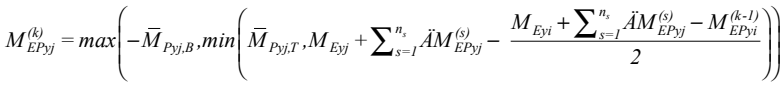

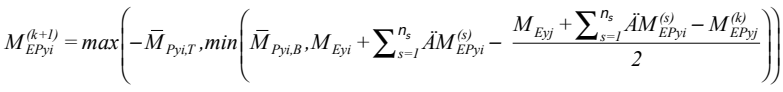

It is worth noting that, when inelastic deformations occur at an intermediate section, eq.(20) and eq.(21) need to be solved iteratively until, in this section, at the iteration loop $k$ 


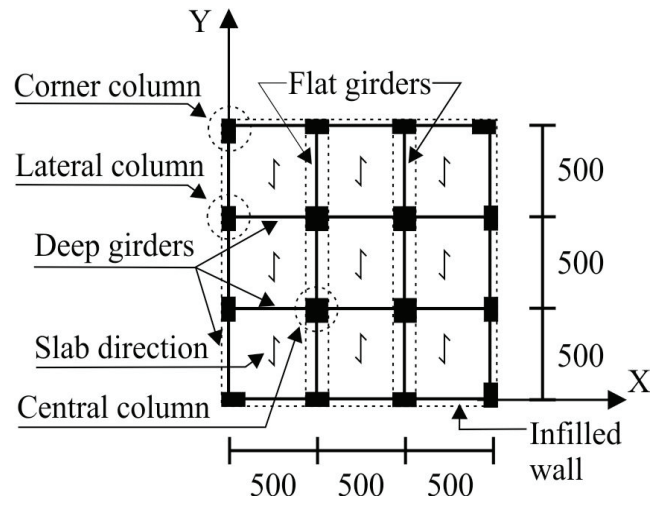

(a) Plan.

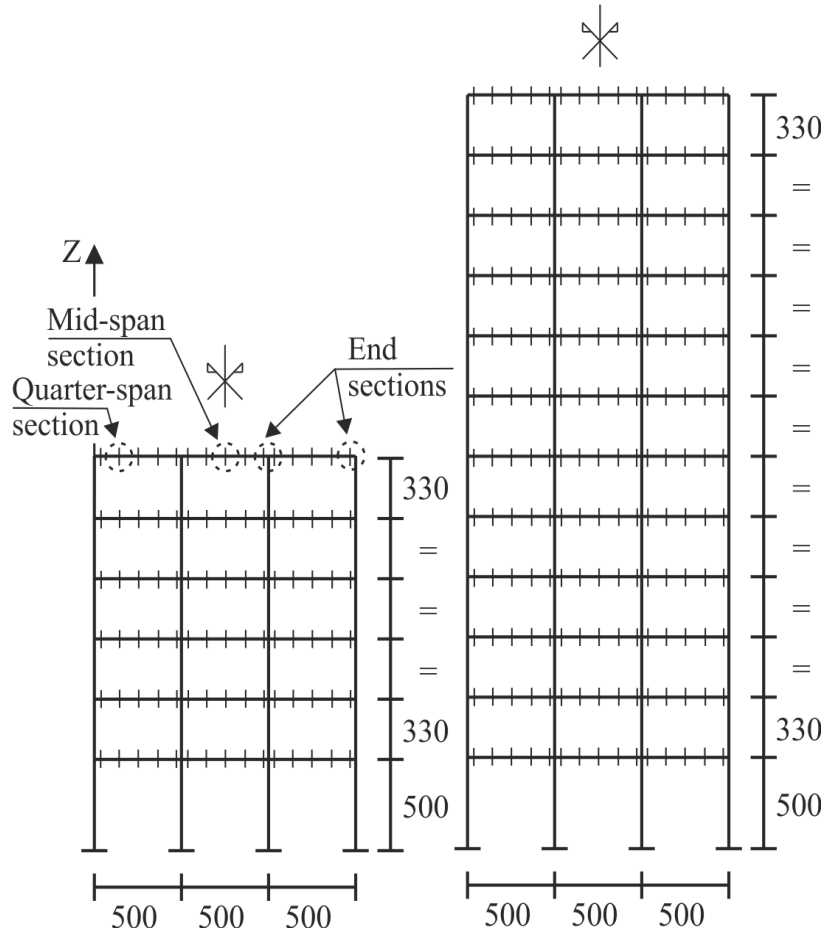

(b) Elevation.

Fig. (4). Six- and twelve-storey r.c. spatial frames (dimensions in $\mathrm{cm}$ ).

Table 1a. Section Dimensions (in $\mathrm{cm}$ ) of the Frame Members: B6LD (in brackets) and B6HD Structures

\begin{tabular}{|c|c|c|c|c|c|}
\hline Storey & Deep Girders & Flat Girders & Corner Columns & Lateral Columns & Central Columns \\
\hline \hline 6,5 & $30 \times 50(30 \times 50)$ & $50 \times 25(50 \times 25)$ & $30 \times 40(30 \times 50)$ & $30 \times 50(30 \times 50)$ & $40 \times 40(40 \times 40)$ \\
\hline 4,3 & $30 \times 60(30 \times 60)$ & $60 \times 25(60 \times 25)$ & $30 \times 50(30 \times 60)$ & $30 \times 60(40 \times 60)$ & $50 \times 50(50 \times 50)$ \\
\hline 2,1 & $40 \times 60(40 \times 60)$ & $70 \times 25(70 \times 25)$ & $40 \times 60(40 \times 70)$ & $40 \times 70(50 \times 80)$ & $60 \times 60(60 \times 60)$ \\
\hline
\end{tabular}

the difference between the plastic moment and the elasticplastic moment evaluated by the equilibrium, starting from the elastic-plastic solution at the end sections, becomes less than a prefixed tolerance.

\section{TEST STRUCTURES AND NEAR-FAULT GROUND MOTIONS}

Typical six- and twelve-storey medium-to-high rise residential buildings, with r.c. framed structure (Fig. 4), are considered as a reference for the numerical investigation. Deep girders are placed along the perimeter of the building together with infilled walls assumed as non-structural elements regularly distributed in elevation; deep and flat girders, perpendicular and parallel to the floor slab direction, respectively, are assumed inside the building (Fig. 4a). Test structures have been designed according to the Italian seismic code (NTC08) assuming, besides the gravity loads, the horizontal seismic loads acting in combination with the vertical ones. Four cases are examined, identifying each building (B) by two symbols: the first one (6 or 12) denotes the number of storeys, the second one (LD or HD) refers to low or high ductility class. Moreover, the following assumptions have been made: medium subsoil (class $\mathrm{B}$, subsoil parameters: $\mathrm{S}_{\mathrm{SH}}=1.13$ in the horizontal direction and $\mathrm{S}_{\mathrm{SV}}=1$ in the vertical one); flat terrain (class T1, topographic parameter: $S_{T}=1$ ); high-risk seismic region (peak ground acceleration in the horizontal, $\mathrm{PGA}_{\mathrm{H}}$, and vertical, $\mathrm{PGA}_{\mathrm{V}}$, directions equal to $0.312 \mathrm{~g}$ and $0.276 \mathrm{~g}$, respectively). The criteria imposed by NTC08 for the regularity in elevation are not always satisfied. As a consequence, the following values of the behavior factor are considered: $\mathrm{q}_{\mathrm{H}}=3.12$ and $\mathrm{q}_{\mathrm{H}}=4.68$, for the horizontal seismic loads, considering low or high ductility class, respectively; $\mathrm{q}_{\mathrm{v}}=1.5$, for the vertical seismic loads. Deadand live-loads used in the design are equal, respectively, to: $4.8 \mathrm{kN} / \mathrm{m}^{2}$ and $2 \mathrm{kN} / \mathrm{m}^{2}$, for the top floor; $5.7 \mathrm{kN} / \mathrm{m}^{2}$ and 2 $\mathrm{kN} / \mathrm{m}^{2}$, for the other floors. Masonry-infill weight is taken into account considering a gravity load of $2.7 \mathrm{kN} / \mathrm{m}^{2}$. A cylindrical compressive strength of $25 \mathrm{~N} / \mathrm{mm}^{2}$ for the concrete and a yield strength of $450 \mathrm{~N} / \mathrm{mm}^{2}$ for the steel are assumed. The sizes of the sections for girders and columns are shown in Table 1a, for B6LD and B6HD structures, and in Table 1b, for B12LD and B12HD structures. The dynamic properties of the test structures are also reported in Table 2: more specifically, the vibration periods corresponding to the three high-participation modes with prevailing components in the horizontal $\left(\mathrm{T}_{1 \mathrm{X}}\right.$ and $\left.\mathrm{T}_{1 \mathrm{Y}}\right)$ or vertical $\left(\mathrm{T}_{1 \mathrm{Z}}\right)$ direction, and the corresponding effective modal masses in the horizontal $\left(\mathrm{m}_{1 \mathrm{X}}\right.$ and $\left.\mathrm{m}_{1 \mathrm{Y}}\right)$ or vertical $\left(\mathrm{m}_{1 \mathrm{Z}}\right)$ direction expressed as a percentage of the total mass $\left(\mathrm{m}_{\mathrm{t}}\right)$ of the test structures. 
Table 1b. Section Dimensions (in $\mathrm{cm}$ ) of the Frame Members: B12LD (in brackets) and B12HD Structures

\begin{tabular}{|c|c|c|c|c|c|}
\hline Storey & Deep Girders & Flat Girders & Corner Columns & Lateral Columns & Central Columns \\
\hline \hline 12 & $30 \times 50(30 \times 50)$ & $50 \times 25(50 \times 25)$ & $30 \times 30(30 \times 30)$ & $30 \times 40(30 \times 40)$ & $40 \times 40(40 \times 40)$ \\
\hline 11 & $30 \times 50(30 \times 50)$ & $50 \times 25(50 \times 25)$ & $30 \times 30(30 \times 30)$ & $30 \times 40(30 \times 40)$ & $40 \times 40(40 \times 40)$ \\
\hline 10 & $30 \times 50(30 \times 50)$ & $60 \times 25(60 \times 25)$ & $30 \times 40(30 \times 40)$ & $30 \times 50(30 \times 50)$ & $50 \times 50(40 \times 40)$ \\
\hline 9 & $30 \times 60(30 \times 60)$ & $60 \times 25(60 \times 25)$ & $30 \times 40(30 \times 40)$ & $30 \times 50(30 \times 50)$ & $50 \times 50(40 \times 40)$ \\
\hline 8 & $30 \times 60(30 \times 60)$ & $70 \times 25(70 \times 25)$ & $30 \times 40(35 \times 40)$ & $30 \times 60(35 \times 60)$ & $50 \times 50(50 \times 50)$ \\
\hline 7 & $30 \times 60(30 \times 60)$ & $70 \times 25(70 \times 25)$ & $30 \times 40(35 \times 40)$ & $30 \times 60(35 \times 60)$ & $60 \times 60(50 \times 50)$ \\
\hline 6 & $40 \times 65(40 \times 65)$ & $80 \times 25(80 \times 25)$ & $40 \times 50(40 \times 50)$ & $40 \times 60(45 \times 60)$ & $60 \times 60(60 \times 60)$ \\
\hline 5 & $40 \times 65(40 \times 65)$ & $80 \times 25(80 \times 25)$ & $40 \times 50(40 \times 50)$ & $40 \times 60(45 \times 60)$ & $60 \times 60(60 \times 60)$ \\
\hline 4 & $40 \times 65(40 \times 65)$ & $90 \times 25(90 \times 25)$ & $40 \times 60(50 \times 60)$ & $40 \times 70(50 \times 70)$ & $70 \times 70(70 \times 70)$ \\
\hline 3 & $40 \times 70(40 \times 70)$ & $90 \times 25(90 \times 25)$ & $40 \times 60(50 \times 60)$ & $40 \times 70(50 \times 70)$ & $70 \times 70(70 \times 70)$ \\
\hline 2 & $40 \times 70(40 \times 70)$ & $100 \times 25(100 \times 25)$ & $50 \times 70(50 \times 70)$ & $50 \times 90(50 \times 90)$ & $80 \times 80(80 \times 80)$ \\
\hline 1 & $40 \times 70(40 \times 70)$ & $100 \times 25(100 \times 25)$ & $50 \times 70(50 \times 70)$ & $50 \times 90(50 \times 90)$ & $80 \times 80(80 \times 80)$ \\
\hline
\end{tabular}

Table 2. Dynamic Properties of the Test Structures

\begin{tabular}{|c|c|c|c|c|c|c|}
\hline Structure & $\mathbf{T}_{\mathbf{1 X}}(\mathbf{s})$ & $\mathbf{T}_{\mathbf{1 Y}}(\mathbf{s})$ & $\mathbf{T}_{\mathbf{1 Z}}(\mathbf{s})$ & $\mathbf{m}_{\mathbf{1 X}} \mathbf{( \% \mathbf { m } _ { \mathbf { t } } )}$ & $\mathbf{m}_{\mathbf{1 Y}} \mathbf{( \% \mathbf { m } _ { \mathbf { t } } )}$ & $\mathbf{m}_{\mathbf{1 Z}}\left(\mathbf{\%} \mathbf{m}_{\mathbf{t}}\right)$ \\
\hline \hline B6LD & 0.576 & 0.698 & 0.064 & 82.3 & 80.7 & 38.5 \\
\hline B6HD & 0.623 & 0.757 & 0.065 & 84.9 & 83.3 & 50.8 \\
\hline B12LD & 0.993 & 1.249 & 0.103 & 69.5 & 70.0 & 64.7 \\
\hline B12HD & 1.000 & 1.272 & 0.103 & 70.6 & 70.3 & 75.6 \\
\hline
\end{tabular}

Table 3. Main Data of the Selected Near-Fault Ground Motions

\begin{tabular}{|c|c|c|c|c|c|c|}
\hline Earthquake & Station & PGA $_{\mathbf{H 1}}$ & $\mathbf{P G A}_{\mathbf{H} \mathbf{2}}$ & $\mathbf{P G A}_{\mathbf{v}}$ & $\boldsymbol{\alpha}_{\mathbf{P G A}, \mathbf{H} 1}$ & $\boldsymbol{\alpha}_{\mathbf{P G A}, \mathbf{H} \mathbf{2}}$ \\
\hline \hline Imperial Valley, 15/10/1979 & El Centro D.A. & $0.352 \mathrm{~g}$ & $0.480 \mathrm{~g}$ & $0.707 \mathrm{~g}$ & 2.009 & 1.473 \\
\hline Northridge, 17/1/1994 & Newhall W.P.C. & $0.426 \mathrm{~g}$ & $0.279 \mathrm{~g}$ & $0.290 \mathrm{~g}$ & 0.682 & 1.040 \\
\hline
\end{tabular}

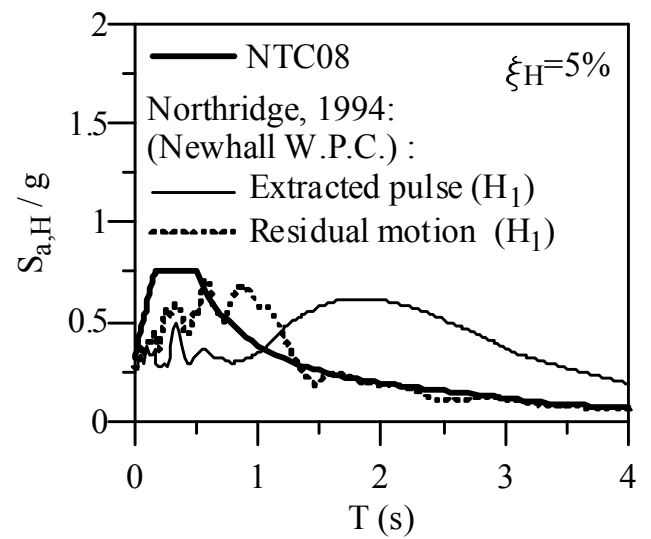

(a) Fault-normal direction.

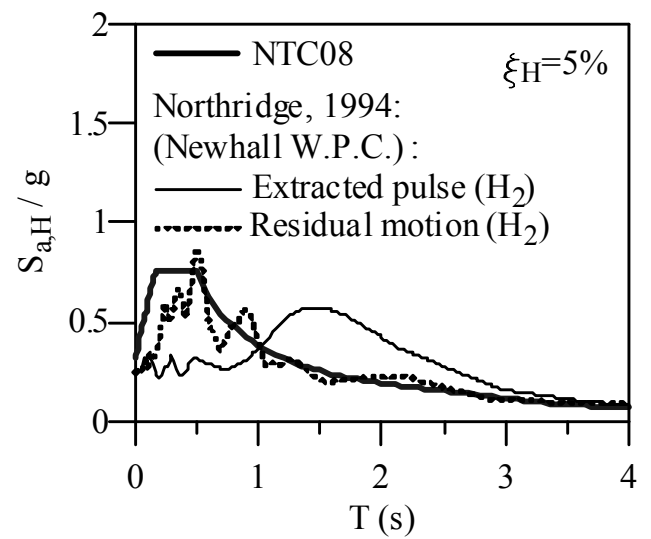

(b) Fault-parallel direction.

Fig. (5). Acceleration (elastic) response spectra: Imperial Valley near-fault ground motion.

In order to study the effects of near-fault ground motions on the nonlinear dynamic response of the test structures, Imperial Valley (El Centro Differential Array station, 1979) and Northridge (Newhall West Pico Canyon station, 1994) ground motions, available in the Next Generation Attenuation database (NGA, 2008) of the Pacific Earthquake Engineering Research center, have been considered [18]. The main corresponding data are reported in Table 3: peak ground acceleration for the two horizontal components $\left(\mathrm{PGA}_{\mathrm{H} 1}\right.$ and $\left.\mathrm{PGA}_{\mathrm{H} 2}\right)$ and the vertical one $\left(\mathrm{PGA}_{\mathrm{V}}\right)$, accelera- tion ratios $\left(\alpha_{\mathrm{PGA}, \mathrm{H} 1}\right.$ and $\left.\alpha_{\mathrm{PGA}, \mathrm{H} 2}\right)$. It is worth noting that the acceleration ratio has a maximum value of 2.009 for the Imperial Valley ground motion as opposed to the value of 1.13 prescribed by NTC08 in the examined case, while the Northridge ground motion shows a velocity pulse with a period equal to $2.4 \mathrm{~s}$ in the fault-normal horizontal direction [19]. The elastic (normalized) response spectra of acceleration in the horizontal $\left(\mathrm{S}_{\mathrm{aH}, 1}\right.$ and $\left.\mathrm{S}_{\mathrm{aH}, 2}\right)$ and vertical $\left(\mathrm{S}_{\mathrm{aV}}\right)$ directions are plotted in Fig. (5) for the Imperial Valley ground motion, assuming an equivalent viscous damping ratio in the 


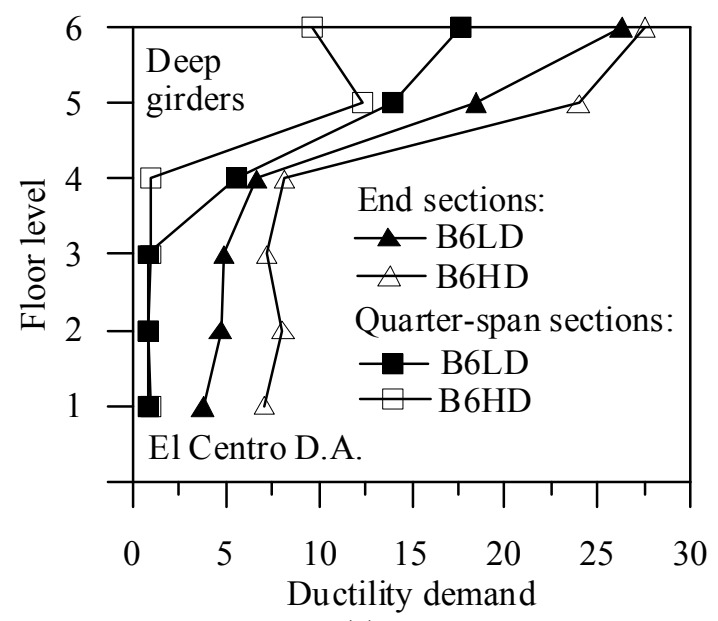

(a)

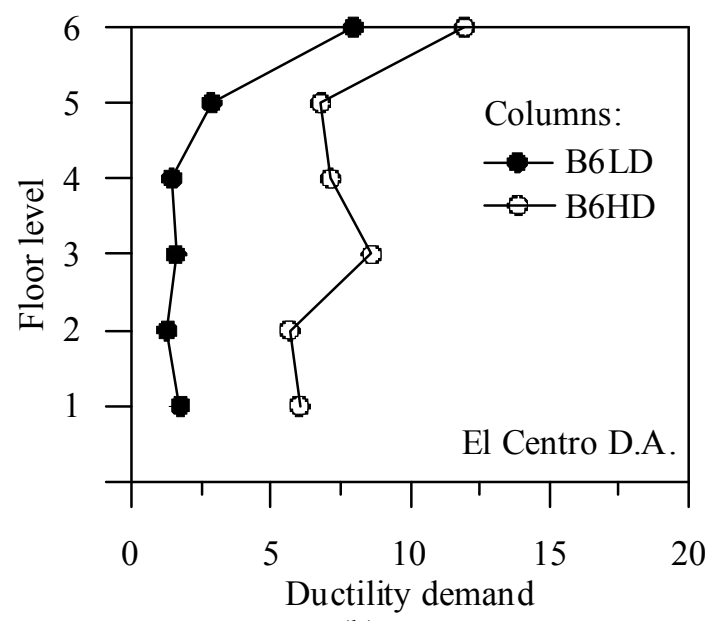

(b)

Fig. (6). Acceleration (elastic) response spectra: Northridge near-fault ground motion.

horizontal direction, $\xi_{H}$, equal to $5 \%$ (Fig. 5a), and an analogous ratio in the vertical direction, $\xi_{V}$, equal to $2 \%$ (Fig. $5 \mathbf{b}$ ). The response spectra of these motions are compared with the corresponding target NTC08 response spectra for a high-risk seismic region and a medium subsoil class. It is interesting to note that in the vertical direction the spectral values of the Imperial Valley ground motion are much greater than those corresponding to NTC08 (Fig. 5b), at least for rather low values of the vibration periods (i.e. $\mathrm{T}_{\mathrm{V}}<0.2 \mathrm{~s}$ ), which are more relevant for the test structures.

Finally, curves analogous to those shown above are represented in Fig. (6), where the elastic (normalized) response spectra of acceleration in the fault-normal (FN) and faultparallel (FP) horizontal directions are plotted for the Northridge ground motion. Following recent seismological studies [20], which allow the extraction of the largest (horizontal) pulse from a near-fault ground motion, two curves are plotted for each direction. As can be observed, in the range of rather long vibration periods (i.e. $\mathrm{T}_{\mathrm{H}} \geq 1.2 \mathrm{~s}$ ), corresponding to the B12LD and B12HD structures which will be examined successively, the spectral values for the extracted pulse (i.e. representing a near-fault motion) are greater than those corresponding to NTC08 and residual motion, especially in the FN direction (Fig. 6a).

\section{NUMERICAL RESULTS}

In order to evaluate the effects produced by horizontal and vertical components of near-fault ground motions on the nonlinear dynamic response of the medium-to-high rise r.c. framed buildings described in the previous section, a numerical investigation is carried out with reference to records of the Imperial Valley and Northridge earthquakes. According to the design hypotheses adopted for the test structures, accelerograms recorded on medium subsoil are considered, with a PGA value comparable with the one prescribed by NTC08, at least for one of the two horizontal directions. A lumped plasticity model based on the Haar-Kàrmàn principle is adopted to model the inelastic behavior of the frame members, considering a two-parameter implicit integration scheme and an initial-stress-like iterative procedure [14]. Plastic conditions are checked at the end sections of the columns, which may experience inelastic deformations due to the horizontal ground motion, approximating the axial forcebiaxial bending moment bounding surface of the elastic domain by 26 flat surfaces. On the other hand, the potential plastic hinges along the span of the girders, due to the vertical ground motion, are taken into account modifying the plastic moments of the end-sections depending on those of the other three selected sections (i.e. the two quarter-span sections and the mid-span section shown in Fig. 4b) and assuming a bilinear moment-curvature law with a hardening ratio $\mathrm{p}=5 \%$. In the Rayleigh hypothesis, the damping matrix is assumed as a linear combination of the mass and stiffness matrices, assuming a viscous damping ratio equal to $5 \%$ or $2 \%$ with reference to the two vibration periods corresponding to high-participation modes with components prevailing in the $Y\left(T_{1 Y}\right)$ or $Z\left(T_{1 Z}\right)$ direction, respectively. In this way, an intermediate value of the damping ratio is achieved in the range of vibration periods $T_{1 Z}-T_{1 Y}$.

Firstly, in order to highlight the effects of the vertical component of near-fault ground motions, the curvature ductility demand of girders and columns, along the height of the six-storey structures, is shown in Fig. (7). Maximum values are considered, assuming that the vertical component of the Imperial Valley ground motion (El Centro D.A. station) acts contemporaneously with the horizontal components applied twice (i.e. alternatively along the principal axes $\mathrm{X}$ and $\mathrm{Y}$ of the building plan). The ductility demand at the end sections and quarter-span sections of the deep girders is reported in Fig. (7a), for both B6LD and B6HD structures. More specifically, the end sections, at the top side, and quarter-span sections, at the bottom one, proved to be the more stressed sections, especially on the upper floors where the effects due to vertical seismic loads generally prevail over those of the horizontal seismic loads and an amplification of the vertical motion is expected. This kind of behavior can be explained by observing that the ductility demand at these sections, in contrast to the mid-span ones, already appears under the horizontal components of the seismic loads. Moreover, the bottom plastic moments of the quarter-span sections, on the upper floors, are less than or equal to those assumed at the mid-span sections. It is worth noting that the ductility demand at the end sections of the B6HD structure is greater than that observed for the B6LD one, while the opposite 


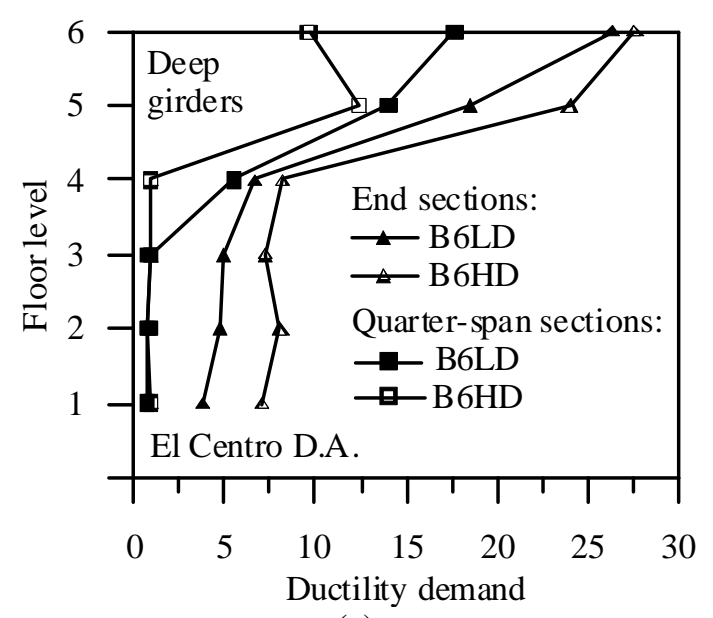

(a)

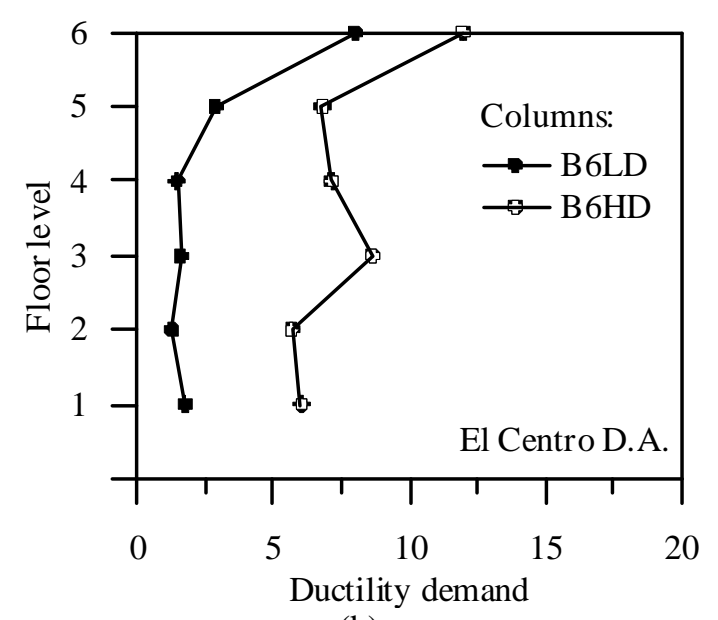

(b)

Fig. (7). Ductility demand for frame members of the six-storey structures subjected to the Imperial Valley motion.

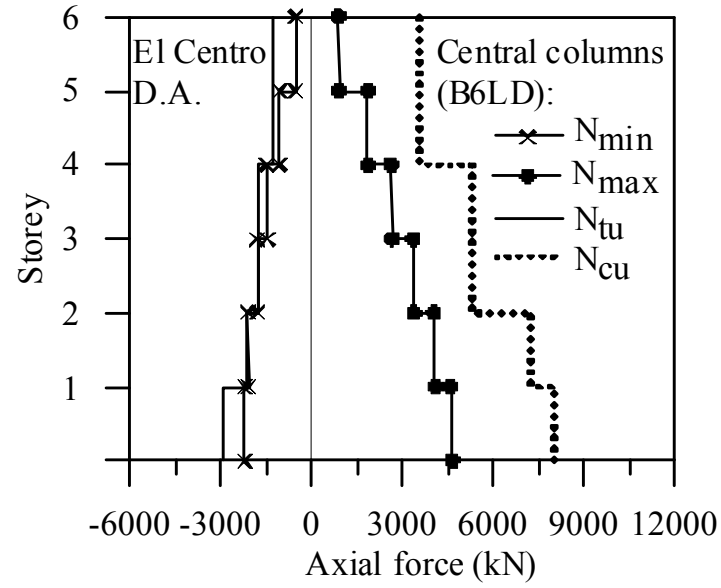

(a)

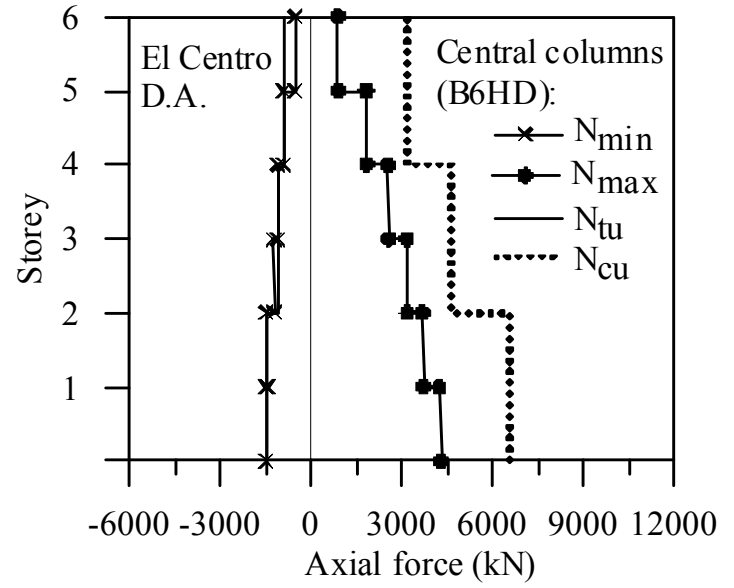

(b)

Fig. (8). Axial forces for columns of the six-storey structures subjected to the Imperial Valley motion.

trend can be seen in the quarter-span sections of the same girders, especially in the upper storeys. This result emphasizes the need to take into account the vertical ground motion in the design of the deep girders, for both low and high ductility classes. Additional results, omitted for the sake of brevity, showed that flat girders exhibit a ductility demand which is practically independent of the vertical ground motion due to their small tributary mass. Curves analogous to those shown above are reported in Fig. (7b), where the maximum ductility demand in the radial direction is evaluated with reference to the columns of the B6LD and B6HD structures. As expected, the ductility demand is acceptable for the B6LD structure, with the exception of the top floor where the "strong-columns weak-girders" mechanism is waived and the inelastic deformations due to the vertical ground motion are more evident. On the other hand, the ductility demand increases for the B6HD structure in spite of the capacity design criterion being more restrictive in this case.

Successively, attention was focused on the axial force attained in the columns, in order to check whether failure phenomena occur under the vertical component of near-fault ground motions: i.e. failure under compression or tension, due to the attainment of the corresponding ultimate compressive load, $\mathrm{N}_{\mathrm{cu}}$, or tensile load, $\mathrm{N}_{\mathrm{tu}}$. For this purpose, the minimum $\left(\mathrm{N}_{\min }\right)$ and maximum $\left(\mathrm{N}_{\max }\right)$ values attained by the axial load (assuming positive to be a compressive load) in the central columns of the B6LD and B6HD structures subjected to the Imperial Valley ground motion are plotted, respectively, in Figs. (8a) and (8b). For these columns, having the greatest tributary mass, the axial-force variation induced a rather high compressive force which in many columns was greater than the balanced load, thus producing a reduction in both the ultimate bending moment and available ductility, and quite close to the ultimate compressive load $\mathrm{N}_{\mathrm{cu}}$, especially on the second and fourth storeys of the B6HD structure (Fig. 8b). Moreover, the vertical ground motion also produced tensile forces, which in many sections of both the B6LD and B6HD structures proved to be very close to the corresponding ultimate tensile force $\mathrm{N}_{\mathrm{tu}}$.

To evaluate the effects of the horizontal components of near-fault ground motions on the local damage undergone by the girders, the ductility demand for the B12LD and B12HD structures subjected to the extracted pulse and residual motion of the Northridge ground motion (Newhall W.P.C. station) are reported in Fig. (9). More specifically, the ductility demand at the end sections is shown in Figs. (9a) and (9b), considering the mean values evaluated with reference to the six-deep and two-flat girders, respectively, at each storey. Fault-normal (FN) and fault-parallel (FP) horizontal components of the Northridge motion are applied along the axes 


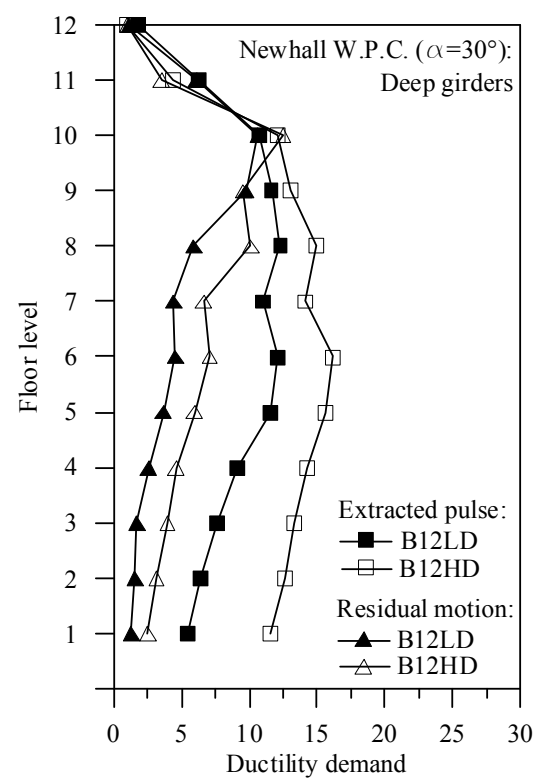

(a)

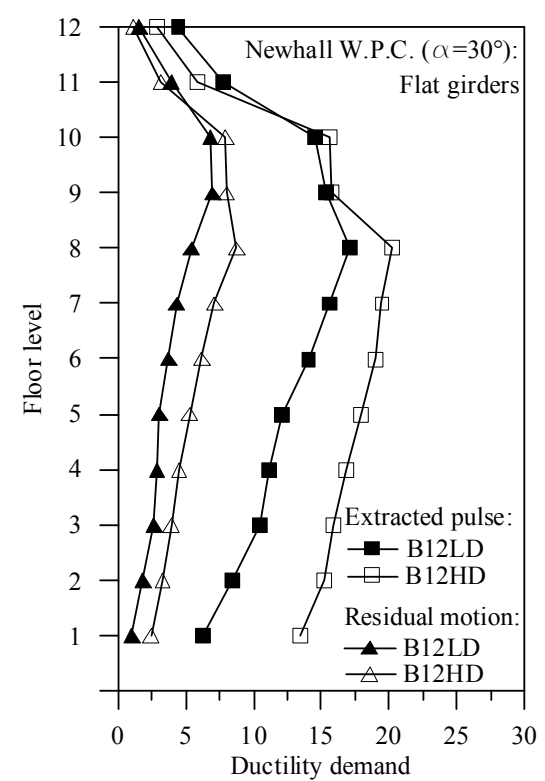

(b)

Fig. (9). Ductility demand for girders of the twelve-storey structures subjected to the Northridge motion.

rotated at $\alpha=30^{\circ}$ with respect to the principal axes $X$ and $Y$ of the building plan. It is worth noting that the ductility demand for the near-fault ground motion (i.e. the extracted pulse) proved to be greater than the corresponding values for the the residual motion, with some exceptions only in the upper three storeys. This result can be explained by observing the structural damage potential relating to a longduration impulsive motion such as that considered in Section 4; in addition, the spectral values for the residual motion are smaller than those evaluated for the extracted pulse, in the range of vibration periods which are more significant for the B12LD and B12HD structures (Fig. 6). As expected, high values of the ductility demand have been obtained for deep and flat girders of the B12HD structure.

Finally, to quantify the damage level related to the excitation angle $(\alpha)$, a ductility index DI $(0 \leq \mathrm{DI} \leq 1)$ of the B12LD and B12HD structures subjected to the extracted pulse of the Northridge ground motion is plotted in Fig. (10). DI is evaluated as the ratio between the mean values of the ductility demand for an assigned angle $\alpha$ and the angle corresponding to the maximum value $\left(\mu_{\max }\right)$; this latter refers to the B12HD structure, in order to have the same normalization for low and high ductility classes.

The DI values for the end sections of deep girders $\left(\mu_{\max }=15.2\right)$, flat girders $\left(\mu_{\max }=14.8\right)$ and columns $\left(\mu_{\max }=5.7\right)$ are plotted in Figs. (10a), (10b) and (10c), respectively. As can be observed, the maximum values of DI occurred at arbitrary fault orientations rather than assuming FN and FP components of the Northridge motion applied along the principal axes of the building plan (i.e. orientation angles $\alpha=0^{\circ}$ and $\alpha=90^{\circ}$ ). This kind of behavior proves to be more evident for flat girders (Fig. 10b) and columns (Fig. 10c). Moreover, the DI spatial domain approximately keeps its shape for deep and flat girders of the B12LD and B12HD structures; some differences can be seen for the columns, where the ductility demand of the B12LD structure is less than half of that of the B12HD structure.

\section{CONCLUSIONS}

The nonlinear seismic response of six- and twelve storey r.c. spatial frames, representative of medium-to-high rise buildings designed according to NTC08, is studied for horizontal and vertical components of near-fault ground motions. More precisely, test structures are designed for medium subsoil and high-risk seismic region, assuming both low and high ductility classes. To describe the inelastic behavior of the r.c. frame members a lumped plasticity model based on the Haar-Kàrmàn principle, representing a satisfactory compromise between accuracy and computational efficiency, is used. The vertical component of near-fault ground motions affected the ductility demand at the end-sections and quarterspan sections of deep girders, especially in the upper storeys and for both ductility classes, while it was negligible for the flat girders with a small tributary mass. Column ductility demand proved to be significant for the high ductility class, in spite of the capacity design based on the "strong-columns weak-girders mechanism" being more restrictive in this case; a large variation in the axial force occurred for the central columns, even producing tension (close to the ultimate tensile force) and high compressive forces. Finally, the pulsetype nature of the horizontal components of near-fault ground motions affected the ductility demand at the end sections of deep and flat girders, especially for high ductility class, and the maximum values of the ductility index for the frame members resulted from arbitrary fault orientations with respect to the building plan. The above considerations indicate that the effects of the horizontal and vertical components of near-fault ground motions should be taken into account through suitable additional code provisions. However, to propose suitable design rules further studies are needed by extending the analysis to other structures and available records of near-fault ground motions.

\section{CONFLICT OF INTEREST}

The authors confirm that this article content has no conflicts of interest. 


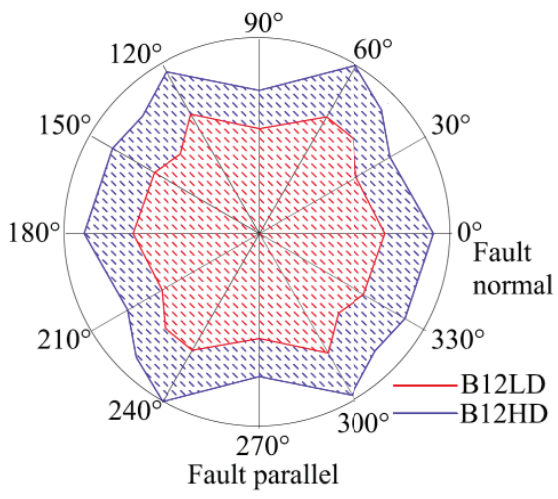

(a) Deep girders.

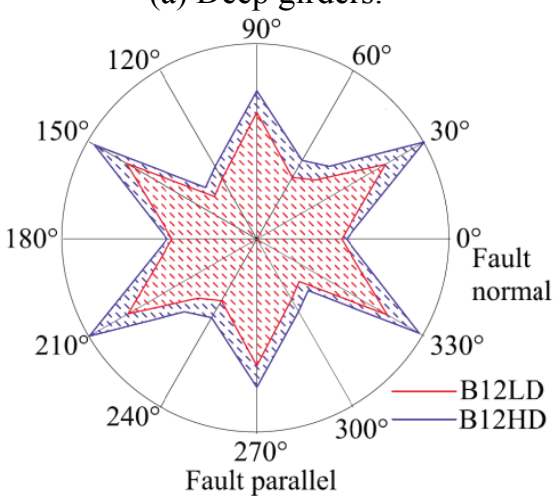

(b) Flat girders

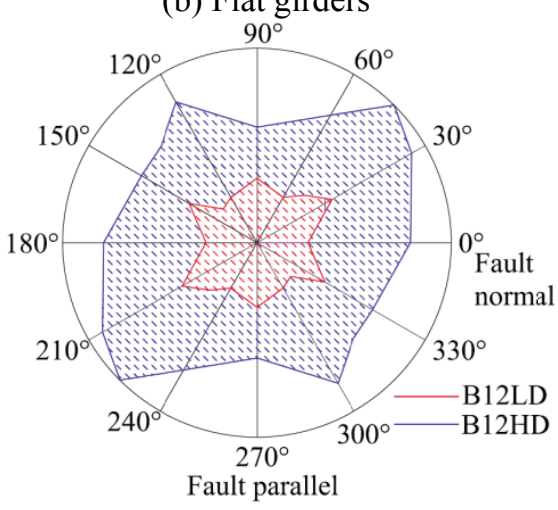

(c) Columns.

Fig. (10). Ductility index of the twelve-storey structures subjected to the extracted pulse of the Northridge motion.

\section{ACKNOWLEDGEMENTS}

The present work was financed by M.I.U.R. (Italian Ministry of Education, University and Research).

\section{REFERENCES}

[1] E. Chioccarelli, and I. Iervolino, "Near-source seismic demand and pulse-like records: a discussion for L'Aquila earthquake", Earthquake Engineering and Structural Dynamics, vol. 39, pp. 10391062,2010
$[2]$

A.J. Papazoglou, and A.S. Elnashai, "Analytical and field evidence of the damaging effect of vertical earthquake ground motion", Earthquake Engineering and Structural Dynamics, vol. 25, pp. 1109-1137, 1996.

[3] A. Baratta, and I. Corbi, "Epicentral distribution of seismic sources over the territory", International Journal of Advances in Engineering Software, vol. 35, no. 10-11, pp. 663-667, 2004.

[4] A. Baratta, and I. Corbi, "Evaluation of the hazard density function at the site", International Journal of Computers \& Structures, vol. 83, no. 28-30, pp. 2503-2512, 2005.

[5] B. Alavi, and H. Krawinkler, "Behavior of moment-resisting frame structures subjected to near-fault ground motions", Earthquake Engineering and Structural Dynamics, vol. 33, pp. 687-706, 2004.

[6] F. Mazza, and A. Vulcano, "Nonlinear dynamic response of r.c. framed structures subjected to near-fault ground motions", Bulletin of Earthquake Engineering, vol. 8, pp. 1331-1350, 2010.

[7] R. Greco, G. Marando and D. Foti, "Strong Motion Duration Effects on Base Isolated Systems", Physica A - Statistical Mechanics And Its Applications, vol. 274, pp. 1-2, 1999.

[8] F. Mazza and A. Vulcano, "Effects of near-fault ground motions on the nonlinear dynamic response of base-isolated r.c. framed buildings", Earthquake Engineering and Structural Dynamics, vol. 41, pp. 211-232, 2012.

[9] L. D. Tirca, D. Foti and M. Diaferio, "Response of middle-rise steel frames with and without passive dampers to near-field ground motions", Engineering Structures, vol. 25, pp. 2, 2003.

[10] F. Mazza, and M. Mazza, "Modeling and nonlinear dynamic Analysis of r.c. spatial frames subjected to bi-directional seismic input", XIII Convegno ANIDIS "L' Ingegneria Sismica in Italia. Bologna (Italy), paper no. 282, 2009.

[11] F. Mazza, and M. Mazza, "Modeling of spatial frames to study the effects of the vertical component of near-fault earthquakes", Proceeding of $14^{\text {th }}$ European Conference on Earthquake Engineering, Skopije (Republic of Macedonia), paper no. 293., 2010.

[12] F. Mazza, and M. Mazza, "Comparative study of the nonlinear response of r.c. spatial frames subjected to near-fault and far-fault ground motions", XIV Convegno ANIDIS, L'Ingegneria Sismica in Italia, Bari (Italy), paper no. 848, 2011.

[13] Technical Regulations for Constructions, (2008). Italian Ministry of the Infrastructures.

[14] F. Mazza, and M. Mazza, "Nonlinear analysis of spatial framed structures by a lumped plasticity model based on the Haar-Kàrmàn principle. Computational Mechanics, vol. 45, pp. 647-664, 2010.

[15] F. Mazza, and M. Mazza, "Nonlinear modeling and analysis of r.c. spatial frames to study the effects of the vertical component of near-fault ground motions", Proceeding of III ECCOMAS Thematic Conference on Computational Methods in Structural Dynamics and Earthquake (COMPDYN 2011), Corfù, Greece, paper no. 322, 2011.

[16] F. Mazza, and M. Mazza, "An efficient nonlinear beam model for the analysis of r.c. spatial frames under vertical component of nearfault ground motions", FIB Symposium (International Federation for Structural Concrete), Concrete Engineering for Excellence and Efficiency, Prague (Czech Republic), vol. 2, pp. 819-822, 2011.

[17] H. Rodrigues, H. Varum, A. Arêde, and A. Costa, "Comparison of different modelling strategies for the representation of nonlinear response of rc columns subjected to biaxial loading", International Conference on Recent Advances in Nonlinear Models - Structural Concrete Applications CoRAN 2011, Coimbra (Portugal), 2011.

[18] Next Generation Attenuation (NGA) database, Pacific Earthquake Engineering Research center, (2008). Available at: http://peer.berkeley.edu-/peer_ground_motion_database.

[19] J.W. Baker, Web page available at http://www. stanford.edu/ bakerjw/.

[20] J.W. Baker, "Quantitative classification of near-fault ground motions using wavelet analysis", Bulletin of the Seismological Society of America, vol. 97, no. 5, pp. 1486-1501, 2007. 